\title{
Erratum to: A system dynamics approach in LCA to account for temporal effects - a consequential energy LCI of car bodies-in-white
}

Peter Stasinopoulos • Paul Compston • Barry Newell • Haley M. Jones

Published online: 16 December 2011

(C) Springer-Verlag 2011

\section{Erratum to: Int J Life Cycle Assess}

DOI 10.1007/s11367-011-0344-0

Title: The title of the manuscript was written incorrectly. The correct title would be:

A system dynamics approach in LCA to account for temporal effects - a consequential energy LCI of car bodies-in-white

("body-in-whites" replaced by "bodies-in-white")

\begin{abstract}
The current (incorrect) sentence is: "The LCI model compares the life-cycle energy consumption of car body-in-whites (BIWs) in Australia made from steel and aluminium."

The phrase should be "bodies-in-white".
\end{abstract}

The online version of the original article can be found at http://dx.doi. org/10.1007/s11367-011-0344-0.

\footnotetext{
P. Stasinopoulos $(\varangle) \cdot$ P. Compston • B. Newell $\cdot$ H. M. Jones Research School of Engineering,

College of Engineering and Computer Science,

The Australian National University,

Canberra ACT 0200, Australia

e-mail: peter.stasinopoulos@anu.edu.au
} 